\title{
Charting the use of electronic health records and other information technologies among child health providers Nir Menachemi ${ }^{* 1}$, Donna L Ettel ${ }^{2}$, Robert G Brooks ${ }^{1}$ and Lisa Simpson ${ }^{2}$
}

Address: ${ }^{1}$ Florida State University College of Medicine, Division of Health Affairs, and Department of Family Medicine and Rural Health, Tallahassee, Florida, USA and ${ }^{2}$ University of South Florida, Department of Pediatrics, Division of Child Health Outcomes, Saint Petersburg, Florida, USA

Email: Nir Menachemi* - nir.menachemi@med.fsu.edu; Donna L Ettel - dettel@hsc.usf.edu; Robert G Brooks - robert.brooks@med.fsu.edu; Lisa Simpson - lsimpso1@hsc.usf.edu

* Corresponding author

Published: 25 July 2006

BMC Pediatrics 2006, 6:21 doi:10.1|86/|47|-243|-6-21
Received: 30 March 2006

Accepted: 25 July 2006

This article is available from: http://www.biomedcentral.com/I47I-243I/6/2I

(C) 2006 Menachemi et al; licensee BioMed Central Ltd.

This is an Open Access article distributed under the terms of the Creative Commons Attribution License (http://creativecommons.org/licenses/by/2.0), which permits unrestricted use, distribution, and reproduction in any medium, provided the original work is properly cited.

\begin{abstract}
Background: Previous studies regarding the use of information technologies (IT) specifically among pediatricians and other physicians who treat children are lacking. As such, the objective of this study is to examine the use of electronic health record (EHR) systems and other IT applications among pediatricians and other child health providers (CHPs) in Florida.
\end{abstract}

Methods: We focus on pediatricians and other CHPs who responded to a state-wide physician survey of IT use. CHPs included general pediatricians, pediatric sub-specialists, and family physicians who self-reported a practice composition of at least $20 \%$ children. We compared general pediatricians to other CHPs and all CHPs (including pediatricians) to other physicians with respect to computer and internet availability, and to the use of personal digital assistants and EHRs. Those with an EHR were also compared regarding the availability of key functions available in their system. Statistical analyses included chi-square analysis and logistic regression models which controlled for numerous factors.

Results: A total of 4,203 surveys (28.2\% response) including I,02I CHPs, were returned. General pediatricians (13.7\%) were significantly less likely to be using an EHR than both CHP family physicians $(26.1 \%)$ and pediatric sub-specialists $(29.6 \%$; $<<.00 \mathrm{I})$. In multivariate analysis, only general pediatricians were significantly less likely than other physicians to indicate the use of an EHR system (OR $=.43 ; 95 \%$ C.I. $=.29-.64)$. Overall, CHPs were less likely to have key functions available in their EHR system including electronic prescribing $(53.3 \%$ vs. $61.9 \% ; p=.028)$, and electronic order entry (47.7\% vs. $57.2 \% ; p=.017)$ among others. General pediatricians and pediatric sub-specialists frequently lagged behind CHP family physicians with respect to key EHR functions. In contrast, CHPs had growth charts ( $51.3 \%$ vs. $24.0 \% ; \mathrm{p}<.00 \mathrm{I})$ and weight-based dosing functions $(35.5 \%$ vs. $22.7 \% ; p<.001)$ more frequently than others.

Conclusion: Physicians caring for children, and especially pediatricians, in Florida, are significantly slower than other doctors to adopt EHRs, and important electronic patient safety functionalities, into their office practices. 


\section{Background}

The use of information technologies promises to improve the overall healthcare system in many ways $[1,2]$. For example, electronic health records (EHRs) and personal digital assistants (PDAs) have been linked to improvements in overall quality in pediatric and adult populations $[3,4]$, a decrease in medical errors [5-8], enhanced financial performance $[9,10]$, improved physician satisfaction [11], and better clinical outcomes $[12,13]$. Other computer applications that can improve the healthcare experience for all parties include emailing between physicians and patients $[14,15]$ (or their family members [16]) as well as Internet connectivity for online access to reference material and health information $[17,18]$.

The overall literature has been growing with reports regarding the use of information technology (IT) in the ambulatory setting. For example, studies of adult populations have demonstrated that EHR systems are available in an estimated 12.9 to $23 \%[18,19]$ of practices serving adults. Moreover, PDA usage among physicians at work has been growing. Currently, estimates of PDA use are $35 \%$ among pediatricians [13] with higher rates among younger doctors [20], residents [21] and medical students. However, despite increasing national attention to the computerization of healthcare in ambulatory settings, several large studies examining IT usage among physicians did not include, or did not separately analyze, pediatricians $[18,19,22]$. Moreover, no study has specifically examined IT utilization among those physicians whose practices see a significant proportion of the approximately 75 million children and adolescents in the U.S.

Along with the increased national attention to IT, a strategic plan has been developed by policymakers and healthcare leaders in the U.S. [23]. The plan, in part, calls for the adoption of EHRs and will require the participation of all physicians, including those who routinely treat children. However, little is known about the current use of IT, especially EHR and PDAs among physicians who treat children. As such, the purpose of the current study is to examine IT use among child health providers (CHPs) in Florida. In the current study CHPs include general pediatricians, family physicians (who treat a significant number of children) and pediatric sub-specialists.

Given the gaps in the literature, we were interested to know if differences existed between these groups and whether or not their collective utilization differed from those physicians who routinely treat adults. Moreover, given the importance of specific EHR capabilities in promoting overall quality and patient safety for children, we examined differences in the availability of these key functions (e.g., clinical notes, medication lists, electronic order entry, etc.) among CHPs and other physician EHR users.
Lastly, we also present data on the barriers to EHR use among these physicians. Given that no previous study has specifically examined a broad group of CHPs, the results of the current study may serve as a benchmark for those interested in charting the progress over time that pediatricians and other CHPs are making toward the widespread adoption of EHRs.

\section{Methods}

In the present study, we specifically focus on child health providers and compare them with all other physicians that participated in a large scale study designed to assess the level of IT use in Florida. Child health providers were defined as general pediatricians, pediatric specialists, and family physicians who self-reported a practice composition of at least $20 \%$ children less than 18 years of age.

During the spring of 2005 a survey (see additional file 1), along with a cover letter, was mailed to 14,921 physicians practicing in the ambulatory setting. This number included all allopathic and osteopathic primary care physicians and a $25 \%$ stratified random sample of specialists with a clear (e.g., not in training) and active Florida medical license. The office address for these physicians was obtained from the current list maintained by the State Department of Health (DOH) for licensure purposes. Because of the nature of the overall study, hospital-based physicians were excluded (e.g., radiologists, pathologists, anesthesiologists, and emergency physicians).

The survey was designed to capture information regarding general IT use and included more in-depth questions regarding EHR use in the office practice location. The survey also included questions about the barriers to EHR use. Those who indicated personally and routinely using EHR were further asked to select from a list those EHR functions that were available to them. This list of EHR functions was derived from the Institute of Medicine's list of standard and desirable EHR functions [2].

Surveys were tracked by a six-digit identification code. Four weeks after the initial mailing, non-respondents were mailed a second cover letter and survey reiterating our interest in their participation. Efforts were made to obtain updated information on addresses from surveys that were returned due to unknown or changed addresses. Those indicating that they were no longer seeing patients were excluded. The questionnaires were mailed back to, and processed by, the Florida State University Survey Research Laboratory where the data was entered into a computer database and subjected to data verification and cross-check methodologies. Additionally, the project received approval from the human subjects committees at the Florida State University and the University of South Florida. 


\section{Statistical analyses}

Data analysis included standard descriptive statistics and chi-square analysis for categorical variables. In addition, to compare CHPs with other physicians with respect to EHR adoption, we utilized binary logistic regression modeling techniques to compute adjusted odds ratios. In the model, control variables included gender, race/ethnicity, age, practice size and type (single vs. multi specialty), as well as geographic location (rural vs. urban). All analyses were computed in SPSS version 13.0 and significance was considered at the $\mathrm{p}<0.05$ level.

To examine physician age, we categorized age by decade. Practice size was categorized similarly to previously published work [19] to allow for comparisons. The categories of practice size included those in solo practice, those with 2-9 physicians, $10-49$ physicians, and 50 or more physicians. To be as accurate as possible, rural physicians were identified using any one of the following three rural criteria: 1) the 33 statutorily-designated rural counties in the state, 2) physicians practicing in rural areas of non-rural counties as designated by the Rural Urban Commuting Area (RUCA) codes [24] and, 3) the current Health Resources and Services Administration list of defined Florida rural zip codes.

Lastly, as recommended by survey research experts [25], we investigated the potential for response bias. To do so, we compared respondents and non-respondents with respect to known demographics, and compared early and late respondents with respect to attributes of the survey that would likely influence participation (e.g., computer savvyness, EHR use, etc.).

\section{Results \\ Demographics}

A total of 4,203 surveys were returned in the overall study for a participation rate of $28.2 \%$. The current sample of interest consisted of 1,021 CHPs, of which 613 were general pediatricians, 138 were family physicians (seeing at least $20 \%$ children), and 270 were pediatric specialists. The remaining 3,159 respondents represented all other ambulatory physicians. The response rates for CHPs, individually and collectively, did not differ from the overall response rate. Demographic and practice characteristics of the CHPs and other physicians are shown in Table 1. Overall, the demographic and practice characteristic of the entire sample were consistent with those of physicians in Florida [26].

Among CHP respondents, average age was 49.5 years with a range of 30-83. The majority of CHPs were male $(64.8 \%)$ and worked in a single specialty (87.7\%) and/or urban $(92.4 \%)$ practice. Moreover, many were either in solo practice $(25.5 \%)$ or had $2-9$ physicians in their groups (60.7\%). An additional $10.7 \%$ and 3.0\% were in groups of $10-49$, or greater than 50 physicians, respectively.

\section{Office-based use of Information Technologies}

When comparing general pediatricians, family physicians, and pediatric specialists, important differences were noted with respect to the use of IT applications in their office practice (see Table 2). For example, the use of an officebased computer was indicated significantly more often by pediatric sub-specialists $(89.3 \%)$ than general pediatricians $(77.4 \%)$ or family physicians $(82.9 \%$; $\mathrm{p}<.001)$. Pediatric sub-specialists were also less likely to have a dialup connection $(7.9 \%)$ as their single method of Internet connectivity when compared with general pediatricians (14.6\%) and family physicians (15.2\%; $\mathrm{p}=.045)$. Lastly, general pediatricians $(13.7 \%)$ were significantly less likely to be using an EHR system than both family physicians $(26.1 \%)$ and pediatric sub-specialists $(29.6 \%$; $<.001)$.

Collectively, CHP respondents did not differ from other physicians in Florida, with respect to the use of many IT applications. However, general pediatricians, specifically, were significantly less likely than other CHPs and other physicians to indicate personally and routinely using an EHR system in their practice $(\mathrm{P}<.001)$. This relationship was present even after controlling for practice size and type, geographic location, and physician age, race and gender $(\mathrm{OR}=.43 ; 95 \%$ C.I. $=.29-.64)$.

When further examining the specific functions available among all physicians who routinely use EHR systems, CHPs differed among themselves, but more frequently from their other physician colleagues in significant ways (see Table 3). For example, CHPs with EHR systems were less likely to indicate having the following functions: allergies $(77.2 \%$ vs. $87.9 \%$; $\mathrm{p}<.001)$, patient scheduling (57.4\% vs. $76.3 \%$; p <.001), electronic prescribing of medications ( $53.3 \%$ vs. $61.9 \% ; \mathrm{p}=.028)$, electronic order entry ( $47.7 \%$ vs. $57.2 \%$; $=.017)$, and electronic connection to pharmacy information for their patients $(31.0 \%$ vs. $40.2 \% ; \mathrm{p}=.018)$. In many of these instances, general pediatricians and pediatric sub-specialists lagged behind family physicians with respect to availability of EHR functions. In contrast, CHPs, overall, reported having pediatric specific functionalities more frequently than other physicians with EHR systems including growth charts (51.3\% vs. $24.0 \%$; $\mathrm{p}<.001)$ and weight-based dosing functions (35.5\% vs.22.7\%; p <.001).

\section{Barriers to the use of EHRs}

We analyzed the barriers among CHP respondents that indicated they were not currently using an EHR system. Generally, while significant differences existed between general pediatricians, family physicians, and pediatric 
Table I: Demographic and practice characteristics of respondents

\begin{tabular}{|c|c|c|}
\hline & Child Health Providers $(\mathrm{N}=1,02 \mathrm{I})$ & Other Physicians $(\mathbf{N}=3,159)$ \\
\hline \multicolumn{3}{|l|}{ Respondent } \\
\hline \multicolumn{3}{|l|}{ Characteristics } \\
\hline Age: Mean (range) & $49.54 \quad(30-83)$ & $51.02 \quad(30-86)$ \\
\hline Gender (male) & $537 \quad(64.8 \%)$ & $1941 \quad(79.7 \%)$ \\
\hline \multicolumn{3}{|l|}{ Race/ethnicity: } \\
\hline Caucasian & $650 \quad(63.7 \%)$ & $2221 \quad(70.3 \%)$ \\
\hline Hispanic & $177 \quad(17.3 \%)$ & 362 (11.5\%) \\
\hline Asian & $119 \quad(11.7 \%)$ & $314 \quad(9.9 \%)$ \\
\hline $\begin{array}{l}\text { African American or } \\
\text { Black }\end{array}$ & $34 \quad(3.3 \%)$ & $99 \quad(3.1 \%)$ \\
\hline Other or unknown & $41 \quad(4.0 \%)$ & $163 \quad(5.2 \%)$ \\
\hline \multicolumn{3}{|l|}{$\begin{array}{l}\text { Practice } \\
\text { Characteristics }\end{array}$} \\
\hline $\begin{array}{l}\text { Mean years practicing in } \\
\text { current community } \\
\text { (range) }\end{array}$ & $|3.5| \quad(1-50)$ & $15.03 \quad(<1-50)$ \\
\hline $\begin{array}{l}\text { Mean years since } \\
\text { medical school } \\
\text { graduation (range) }\end{array}$ & $20.69 \quad(<1-59)$ & $21.67 \quad(<1-62)$ \\
\hline \multicolumn{3}{|l|}{ Practice Size: } \\
\hline Solo practice & $247 \quad(25.5 \%)$ & $980 \quad(32.7 \%)$ \\
\hline 2-9 physicians & $588 \quad(60.7 \%)$ & $156 \mid \quad(52.1 \%)$ \\
\hline 10-49 physicians & $104 \quad(10.7 \%)$ & $279 \quad(9.3 \%)$ \\
\hline $\begin{array}{l}50 \text { or greater } \\
\text { physicians }\end{array}$ & $29 \quad(3.0 \%)$ & $177 \quad(5.9 \%)$ \\
\hline \multicolumn{3}{|l|}{ Practice setting: } \\
\hline Rural & 77 (7.6\%) & $168 \quad(5.3 \%)$ \\
\hline Urban & $942 \quad(92.4 \%)$ & $2985 \quad(94.7 \%)$ \\
\hline Single specialty & $591 \quad(87.7 \%)$ & $2121 \quad(85.0 \%)$ \\
\hline Multi specialty & $83 \quad(12.3 \%)$ & 374 (15.0\%) \\
\hline
\end{tabular}

Note: Where applicable, numbers may not add up to $100 \%$ due to rounding

sub-specialists; similar trends in barriers existed (see Table 4). For example, 'up front cost of hardware/software' was the single most frequent barrier among each of the CHP groups. However, this barrier was most frequent among general pediatricians $(60.4 \%$ vs. $55.3 \%$ for FPs, and $38.6 \%$ for pediatric sub-specialists). In addition to other financial barriers, notable barriers for all three CHP groups included issues related to the fact that data entry could be cumbersome, and the lack of time needed to acquire and implement an EHR system. Overall, general pediatricians, more frequently than the other CHPs, indicated that each barrier to EHR was 'major.'

\section{Discussion}

In the context of significant increases in public and private sector attention and resources devoted to promoting the adoption of EHRs and other IT platforms, it is critical to understand where we stand currently in the uptake of these technologies among those serving children. The present study is, to our knowledge, the first of its kind to demonstrate on a statewide basis what many have reported anecdotally or in single site studies - namely that general pediatricians are significantly slower to incorporate EHRs into their office practice than other physicians. It also provides the first quantitative estimate of the proportion of physicians who have access to essential functionalities including those specific to pediatric patients [27] (e.g., growth charts and weight based dosing).

There are many factors that likely contribute to the slow rate of adoption among general pediatricians. Compared to family physicians, general pediatricians in our sample were significantly more likely to practice in solo or small practices (data not shown), which has been shown to be associated with slower adoption of EHRs $[18,19]$. Pediatric sub-specialists did not differ significantly from general pediatricians with respect to practice size configurations. However, after controlling for practice size, and other factors, pediatricians were still less likely to be EHR users than both family physicians and pediatric sub-specialists. A possible explanation may be related to the initial startup and ongoing maintenance costs of EHRs to physician practices $[28,29]$. Given that general pediatricians have the lowest median incomes of all physicians [30] and 
Table 2: Percent information technology availability among child health providers $(n=I, 02 I)$ in Florida.

\begin{tabular}{|c|c|c|c|c|c|c|}
\hline \multirow[b]{2}{*}{$\begin{array}{l}\frac{\text { Information }}{\text { Technology }} \\
\text { Available }\end{array}$} & \multicolumn{3}{|c|}{ Child Health Providers (CHPs) } & \multirow[b]{2}{*}{$\begin{array}{l}\text { Differences among } \\
\text { CHPs' } \text { P-value }\end{array}$} & \multirow[b]{2}{*}{$\begin{array}{c}\text { All other } \\
\text { Physicians }(n= \\
3,159)\end{array}$} & \multirow[b]{2}{*}{$\begin{array}{c}\text { Difference } \\
\text { between CHPs } \\
\text { and all other } \\
\text { Physicians'P. } \\
\text { value }\end{array}$} \\
\hline & $\begin{array}{c}\text { General } \\
\text { Pediatricians (n } \\
=613)\end{array}$ & $\begin{array}{c}\text { Family } \\
\text { Physicians* } \\
\text { I38) }\end{array}(n=$ & $\begin{array}{l}\text { Pediatric Sub- } \\
\text { specialists }(n= \\
270)\end{array}$ & & & \\
\hline $\begin{array}{l}\text { Office-based } \\
\text { Computer }\end{array}$ & 77.4 & 82.9 & 89.3 & $<.001$ & 81.0 & .772 \\
\hline Internet Access & 96.7 & 97.7 & 97.6 & .708 & 96.3 & .246 \\
\hline $\begin{array}{l}\text { Dial-up } \\
\text { connection } \\
\text { only }\end{array}$ & 14.6 & 15.2 & 7.9 & .045 & 11.9 & .454 \\
\hline $\begin{array}{l}\text { High-speed } \\
\text { connection }\end{array}$ & 83.4 & 81.1 & 89.2 & .089 & 85.6 & .514 \\
\hline $\begin{array}{l}\text { Email with patients } \\
\text { (or family } \\
\text { members) }\end{array}$ & 14.4 & 20.4 & 16.8 & .198 & 16.8 & .539 \\
\hline $\begin{array}{l}\text { Practice has a } \\
\text { website }\end{array}$ & 43.0 & 46.0 & 44.4 & .795 & 42.0 & .356 \\
\hline $\begin{array}{l}\text { Personal Digital } \\
\text { Assistant (PDA) }\end{array}$ & 38.3 & 39.5 & 37.9 & .951 & 37.2 & .499 \\
\hline $\begin{array}{l}\text { Electronic Health } \\
\text { Records (EHR) }\end{array}$ & 13.7 & 26.1 & 29.6 & $<.001$ & 24.8 & .001 \\
\hline
\end{tabular}

*Family physicians with at least $20 \%$ children $(<18$ years of age) in their practice.

'Chi square test used to identify differences among groups

often rely heavily on Medicaid reimbursements which are well below those of Medicare, they may not be able to overcome many of the financial burdens necessary to adopt EHR. In our sample, general pediatricians rated financial barriers as a major barrier to EHR significantly more often than other CHPs and were significantly more likely to report that there practice was comprised of a higher percentage of Medicaid patients (data not shown). Nevertheless, while financial barriers are clearly sizable, other important barriers exist as well. For example, the lack of time needed to acquire and implement and EHR system, which was among the top barriers for all CHPs, is particularly problematic for general pediatricians who indicated this barrier most frequently. Overall, a better understanding of adoption barriers among child health providers is warranted. It should be noted, that our group has utilized the data representing all the physicians from the current study (not just CHPs), in a more in-depth analysis examining barriers to EHR systems by physicians. That study, which is forthcoming in a separate journal, examined barriers among physicians of differing adoption intentions [31]. Similarly, pediatric and health quality researchers should focus on this issue of barriers to greatly benefit the national debate on EHR use.

Much of the patient safety and quality improvement benefits associated with EHR use are attributable to key functions available in many systems. These functions include, but are not limited to, clinical decision support, preventive service reminders, electronic order and prescription entry, allergy and medication lists, and electronic connection to other sources of clinical data (i.e., pharmacy or laboratory). EHR systems lacking some or more of these important functions may not provide the same overall patient safety and quality related benefits. In the present study, we find that general pediatricians are significantly less likely to routinely use an EHR system. Moreover, when an EHR system was present, general pediatricians and pediatric sub-specialists were significantly less likely than other doctors, including family physicians, to report the presence of key patient safety function such as electronic prescription and order entry, allergy lists, and connections to information from local pharmacies.

Given that EHRs and these key functionalities hold significant promise for improving the quality and safety of health care, the implication of our findings is that the quality and safety of care for children and adolescents may not improve as quickly as for other populations unless specific attention is paid to the needs of child health providers and child health care. It should be noted that many EHR vendors may not have designed their systems around pediatric needs. If so, present functions in EHR systems may be more difficult to use in pediatric patients. 
Table 3: Availability of specific electronic functions in EHR equipped practices in Florida.

\begin{tabular}{|c|c|c|c|c|c|c|}
\hline \multirow[b]{2}{*}{$\begin{array}{l}\text { Percent EHR Systems with } \\
\text { the following functions: }\end{array}$} & \multicolumn{3}{|c|}{ Child Health Providers (CHPs) } & \multirow[b]{2}{*}{$\begin{array}{l}\text { Differences among } \\
\text { CHPs' P-value }\end{array}$} & \multirow[b]{2}{*}{$\begin{array}{l}\text { All other } \\
\text { Physicians } \\
(n=785)\end{array}$} & \multirow[b]{2}{*}{$\begin{array}{c}\text { Difference } \\
\text { between CHPs and } \\
\text { all other } \\
\text { Physicians'P-value }\end{array}$} \\
\hline & $\begin{array}{c}\text { General } \\
\text { Pediatricians } \\
(n=83)\end{array}$ & $\begin{array}{c}\text { Family } \\
\text { Physicians* } \\
(n=36)\end{array}$ & $\begin{array}{l}\text { Pediatric } \\
\text { Sub- } \\
\text { specialists } \\
(n=80)\end{array}$ & & & \\
\hline Clinical notes & 90.1 & 97.2 & 85.7 & .170 & 93.4 & .089 \\
\hline Patient demographics & 85.2 & 97.2 & 85.7 & .152 & 89.2 & .571 \\
\hline Diagnosis & 84.0 & 91.7 & 83.1 & .462 & 86.6 & .619 \\
\hline Medication lists & 86.4 & 97.2 & 77.6 & .023 & 88.1 & .204 \\
\hline Allergies & 79.0 & 100 & 64.9 & $<.001$ & 87.9 & $<.001$ \\
\hline Problem list & 74. 1 & 97.2 & 70.1 & .005 & 80.8 & .148 \\
\hline Procedures & 79.0 & 75.0 & 71.4 & .543 & 77.2 & .544 \\
\hline $\begin{array}{l}\text { Electronically available lab data/ } \\
\text { results }\end{array}$ & 63.0 & 72.2 & 55.8 & .239 & 68.7 & .092 \\
\hline $\begin{array}{l}\text { Electronically available x-ray } \\
\text { results }\end{array}$ & 61.7 & 61.1 & 50.6 & .324 & 59.8 & .624 \\
\hline Patient scheduling & 58.0 & 86.1 & 42.9 & $<.001$ & 76.3 & $<.001$ \\
\hline $\begin{array}{l}\text { Electronic prescribing of } \\
\text { medications }\end{array}$ & 54.3 & 66.7 & 46.8 & .139 & 61.9 & .028 \\
\hline Growth charting & 61.7 & 58.3 & 37.7 & .007 & 24.0 & $<.001$ \\
\hline Electronic order entry & 48. 1 & 58.3 & 41.6 & .247 & 57.2 & .017 \\
\hline Patient education materials & 49.4 & 61.1 & 40.3 & .111 & 45.0 & .419 \\
\hline Offsite access/log-in capability & 50.6 & 50.0 & 33.8 & .073 & 45.0 & .736 \\
\hline Coding advice to physicians & 42.0 & 50.0 & 35.1 & .308 & 35.9 & .224 \\
\hline Access to reference material & 30.9 & 52.8 & 39.0 & .078 & 37.9 & .959 \\
\hline Weight-based dosing calculations & 44.4 & 30.6 & 28.6 & .090 & 22.7 & $<.001$ \\
\hline $\begin{array}{l}\text { Electronic connection to } \\
\text { pharmacy info }\end{array}$ & 30.9 & 33.3 & 28.6 & .871 & 40.2 & .018 \\
\hline Preventive service reminders & 28.4 & 52.8 & 20.8 & .002 & 35.3 & .123 \\
\hline Clinical decision support & 28.4 & 30.6 & 19.5 & .314 & 25.2 & .933 \\
\hline $\begin{array}{l}\text { Auto-updated insurance coverage } \\
\text { info }\end{array}$ & 19.8 & 16.7 & 11.7 & .381 & 17.0 & .668 \\
\hline Advance directives & II.I & 25.0 & 7.8 & .032 & 25.0 & $<.001$ \\
\hline
\end{tabular}

*Family physicians with at least $20 \%$ children $(<18$ years of age) in their practice.

'Chi square test used to identify differences among groups

The information in the present study may be limited in several ways. The generalizability of our research may be limited by the cross-sectional nature of this single state study. Additionally, we recognize that the potentially low response rate may be a limiting factor. However, after employing established methodologies to detect bias, we found no evidence of response bias in our sample [32]. Nevertheless, the possibility always exists that physicians who participated in our study by completing the six-page questionnaire were more interested in IT than those who chose not to participate. If that were the case, our findings may be an overestimate of overall adoption rates. However, it is important to note that our response rate is comparable to published studies utilizing survey methodologies with physicians [25,33]. In addition, Florida may differ from other states in ways that could plausibly affect IT adoption. For example, the Governor established a health information technology advisory board in 2003, which has met around the state with key stakeholders, and may have raised the visibility and focus on IT over the last two years.

\section{Conclusion}

We hope our study will support action on the part of all those interested in promoting the adoption of IT to improve the quality and safety of care for children. In the last two years alone, a number of new groups have formed nationally to promote the adoption of EHRs. Child health representatives have been involved in some, but not all of these activities. In particular, we hope that these data will be used to support the following actions:

1. Advocacy for an increase in the proportion of federal resources dedicated to EHR adoption that is child specific. Despite continued efforts to the contrary, a decreasing proportion of the AHRQ budget includes a focus of chil- 
Table 4: Barriers to the use of electronic health records among child health providers in Florida

\begin{tabular}{|c|c|c|c|c|}
\hline & General Pediatricians & Family Physicians* & Pediatric Sub-specialists & P-valuel \\
\hline \multicolumn{5}{|l|}{ Financial barriers } \\
\hline - Upfront cost of hardware/software are too high & $60.4 \%$ & $55.3 \%$ & $38.6 \%$ & $<.001$ \\
\hline - Ongoing maintenance costs would be too high & $42.1 \%$ & $36.9 \%$ & $25.9 \%$ & $<.001$ \\
\hline - Inadequate Return on Investment (ROI) & $40.3 \%$ & $31.4 \%$ & $28.2 \%$ & $<.001$ \\
\hline \multicolumn{5}{|l|}{ Productivity barriers } \\
\hline - Entering data into computer can be cumbersome & $47.0 \%$ & $38.7 \%$ & $31.7 \%$ & $<.001$ \\
\hline - Lack of time to acquire, implement such a system & $42.6 \%$ & $37.2 \%$ & $31.3 \%$ & $<.001$ \\
\hline - EHR may slow me down & $34.5 \%$ & $34.1 \%$ & $17.8 \%$ & $<.001$ \\
\hline $\begin{array}{l}\text { - Temporary loss of productivity and/or revenue } \\
\text { during EHR system implementation phase }\end{array}$ & $30.8 \%$ & $30.6 \%$ & $16.3 \%$ & $<.001$ \\
\hline $\begin{array}{l}\text { - Disrupts workflow and/or office's physical layout to } \\
\text { accommodate going to a computerized system }\end{array}$ & $28.8 \%$ & $21.3 \%$ & $13.2 \%$ & $<.001$ \\
\hline - No time to learn how to use such a system & $21.0 \%$ & $17.1 \%$ & $13.6 \%$ & $<.001$ \\
\hline - The system would be difficult to use & $18.5 \%$ & $15.8 \%$ & $7.9 \%$ & $<.001$ \\
\hline \multicolumn{5}{|l|}{ Technical barriers } \\
\hline - Lack of uniform data standards within the industry & $42.5 \%$ & $32.0 \%$ & $32.4 \%$ & $<.001$ \\
\hline $\begin{array}{l}\text { - Temporary loss of access to patient records if } \\
\text { computer crashes or power fails }\end{array}$ & $41.0 \%$ & $30.3 \%$ & $26.3 \%$ & $<.001$ \\
\hline - Products available do not meet my needs & $25.7 \%$ & $19.8 \%$ & $24.4 \%$ & 0.045 \\
\hline $\begin{array}{l}\text { - Me and/or my staff don't have any technical } \\
\text { knowledge }\end{array}$ & $13.5 \%$ & $9.8 \%$ & $10.0 \%$ & 0.001 \\
\hline \multicolumn{5}{|l|}{ Patients barriers } \\
\hline $\begin{array}{l}\text { - Privacy/confidentiality concerns (i.e., electronic } \\
\text { records not secure) }\end{array}$ & $19.0 \%$ & $18.9 \%$ & $18.4 \%$ & 0.004 \\
\hline $\begin{array}{l}\text { - Patient resistance or not wanting their physicians to } \\
\text { use EHR }\end{array}$ & $4.9 \%$ & $4.2 \%$ & $6.5 \%$ & 0.006 \\
\hline
\end{tabular}

Note: Value in cells represents the percentage of respondents who indicated each item was a major barrier to the adoption of electronic health records.

*Family physicians with at least $20 \%$ children $(<18$ years of age) in their practice.

'Chi square test used to identify differences among groups

dren. Several bills are currently before Congress to address IT and these should include specific provisions to help child health providers adopt EHRs.

2. Increased representation by child health experts in national IT and IT standards organizations - thanks to the efforts of groups such as the American Academy of Pediatrics, the Child Health Corporation of America and the National Initiative for Children's Healthcare Quality, the voice of pediatrics is now being heard much more often at venues where IT is being discussed. This needs to continue and grow.

3. Increased attention by vendors to building pediatric specific functionalities into their products, such as weight based dosing and growth charting; and

4. Increased involvement by practicing child health providers in on-going efforts to reward the use of clinical IT in pay-for-performance programs and to design ways to overcome the non-financial barriers as well.

It is our hope that if this study were to be repeated in five years, we would find that we have closed the EHR-divide between pediatrics and all other specialties. This will not happen without concerted action on the part of child health providers and the organizations that represent them.

\section{Competing interests}

The author(s) declare that they have no competing interests.

\section{Authors' contributions}

$\mathrm{NM}, \mathrm{RGB}$, and LS developed the survey instrument. NM conducted the statistical analyses and wrote the first draft of the manuscript. NM, RGB and LS drafted subsequent versions of the manuscript. All author helped interpret the results of the analyses, and all authors read and approved the final manuscript. 


\section{Additional material}

\section{Additional File 1}

'Florida Ambulatory IT survey'. This PDF file is a copy of the survey instrument used in the current study.

Click here for file

[http://www.biomedcentral.com/content/supplementary/14712431-6-21-S1.pdf]

\section{Acknowledgements}

This project was funded by the Center for Medicare and Medicaid Services (CMS), United States Department of Health and Human Services, Under Contract Number 500-02 FL02.

The funding agency played no role in the study design, data collection, analyses, or interpretation of the data. The funding agency had no role in the preparation or submission of this manuscript.

\section{References}

I. IOM: Crossing the quality chasm: A new health system for the 2 I st century. In Book Crossing the quality chasm: A new health system for the 2 Ist century (Editor ed.^^eds.) City: Institute of Medicine; 2001.

2. Aspden P: Patient safety achieving a new standard for care. Washington, D.C.: National Academies Press; 2004.

3. Adams WG, Mann AM, Bauchner $\mathrm{H}$ : Use of an electronic medical record improves the quality of urban pediatric primary care. Pediatrics 2003, III:626-32.

4. Bates DW, Ebell M, Gotlieb E, Zapp J, Mullins HC: A proposal for electronic medical records in U.S. primary care. J Am Med Inform Assoc 2003, 10: I- 10.

5. Bates DW, Cohen M, Leape LL, Overhage JM, Shabot MM, Sheridan $\mathrm{T}$ : Reducing the frequency of errors in medicine using information technology. J Am Med Inform Assoc 200I, 8:299-308.

6. Fischer S, Stewart TE, Mehta S, Wax R, Lapinsky SE: Handheld computing in medicine. J Am Med Inform Assoc 2003, 10:139-49.

7. Galt K, Rich E, Young W: Impact of hand-held technologies on medication errors in primary care. Book Impact of hand-held technologies on medication errors in primary care (Editor ed.^^eds.), City 2002, 23:7I-8I.

8. Rothschild JM, Lee TH, Bae T, Bates DW: Clinician use of a palmtop drug reference guide. J Am Med Inform Assoc 2002, 9:223-9.

9. Barlows S, Johnson J, Steck J: The economic effect of implementing an EMR in an outpatient clinical setting. J Healthc Inf Manag 2004, I 8:46-5I.

10. Wang SJ, Middleton B, Prosser LA, Bardon CG, Spurr CD, Carchidi PJ, Kittler AF, Goldszer RC, Fairchild DG, Sussman AJ, et al.: A costbenefit analysis of electronic medical records in primary care. Am J Med 2003, I I 4:397-403.

II. Sittig DF, Kuperman GJ, Fiskio J: Evaluating physician satisfaction regarding user interactions with an electronic medical record system. Proc AMIA Symp 1999:400-4.

12. Burton L, Anderson G, Kues I: Using Electronic Health Records to Help Coordinate Care. Milbank Quarterly 2004, 82:457-8I.

13. Carroll AE, Christakis DA: Pediatricians' use of and attitudes about personal digital assistants. Pediatrics 2004, I I 3:238-42.

14. Car J, Sheikh A: Email consultations in health care: I - scope and effectiveness. Bmj 2004, 329:435-8.

15. Houston TK, Sands DZ, Jenckes MW, Ford DE: Experiences of patients who were early adopters of electronic communication with their physician: satisfaction, benefits, and concerns. Am J Manag Care 2004, 10:60I-8.

16. Anand SG, Feldman MJ, Geller DS, Bisbee A, Bauchner H: A content analysis of e-mail communication between primary care providers and parents. Pediatrics 2005, I I 5: | 283-8.

17. Chew F, Grant W, Tote R: Doctors on-line: using diffusion of innovations theory to understand internet use. Fam Med 2004, 36:645-50.
18. Miller RH, Hillman JM, Given RS: Physician use of IT: results from the Deloitte Research Survey. J Healthc Inf Manag 2004, 18:72-80.

19. Audet AM, Doty MM, Peugh J, Shamasdin J, Zapert K, Schoenbaum S: Information technologies: when will they make it into physicians' black bags? MedGenMed 2004, 6:2.

20. Martin S: More than half of MDs under age 35 now using PDAs. Cmaj 2003, 169:952.

21. Criswell DF, Parchman ML: Handheld computer use in U.S. family practice residency programs. J Am Med Inform Assoc 2002, 9:80-6.

22. Gans D, Kralewski J, Hammons T, Dowd B: Medical groups' adoption of electronic health records and information systems. Health Aff (Millwood) 2005, 24:1323-33.

23. Brailer DJ: The decade of health information technology: Delivering consumer-centric and information-rich health care. In Book The decade of health information technology: Delivering consumer-centric and information-rich health care. (Editor ed.^eds.) City: Office for the National Coordinator for Health Information Technology; 2004

24. Morrill R, Cromartie J, Hart L: Metropolitan, Urban, and Rural Commuting Areas: Toward a Better Depiction of the U.S. Settlement System. Urban Geography 1999, 20:727-748.

25. Asch DA, Jedrziewski MK, Christakis NA: Response rates to mail surveys published in medical journals. J Clin Epidemiol 1997, 50: II29-36.

26. Pasko T, Smart D: Physician Characteristics and Distribution in the US. In Book Physician Characteristics and Distribution in the US (Editor ed.^eds.) City: American Medical Association; 2004.

27. American Academy of Pediatrics: Task Force on Medical Informatics. Special requirements for electronic medical record systems in pediatrics. Pediatrics 200I, 108:5I3-5.

28. Valdes I, Kibbe DC, Tolleson G, Kunik ME, Petersen LA: Barriers to proliferation of electronic medical records. Inform Prim Care 2004, 1 2:3-9.

29. Hersh W: Health care information technology: progress and barriers. Jama 2004, 292:2273-4.

30. Kane C, Loeblich H: Physician Income: The Decade in Review. In Physician Socioeconomic Statistics Chicago, Illinois: American Medical Association; 2003.

31. Menachemi N: Barriers to Ambulatory EHR: Who are "imminent adopters" and how do they differ from other physicians? Informatics in Primary Care 2006 in press.

32. Menachemi N, Hikmet N, Stutzman M, Brooks RG: Investigating response bias in a health information technology survey of physicians. Journal of Medical Systems 2006 in press.

33. Kellerman SE, Herold J: Physician response to surveys. A review of the literature. Am J Prev Med 200I, 20:6I-7.

\section{Pre-publication history}

The pre-publication history for this paper can be accessed here:

http://www.biomedcentral.com/1471-2431/6/21/prepub

Publish with Biomed Central and every scientist can read your work free of charge

"BioMed Central will be the most significant development for disseminating the results of biomedical research in our lifetime. "

Sir Paul Nurse, Cancer Research UK

Your research papers will be:

- available free of charge to the entire biomedical community

- peer reviewed and published immediately upon acceptance

- cited in PubMed and archived on PubMed Central

- yours - you keep the copyright

Submit your manuscript here:

http://www.biomedcentral.com/info/publishing_adv.asp 